\title{
O convívio de adolescentes em medida socioeducativa de internação com a equipe técnica
}

\author{
Vinicius Coscioni \\ Universidade Federal do Espirito Santo, ES, Brasil e \\ Universidade Federal do Rio Grande do Sul, RS, Brasil \\ Bruno Graebin de Farias \\ Universidade Federal do Rio Grande do Sul, RS, Brasil \\ Agnaldo Garcia \\ Edinete Maria Rosa \\ Universidade Federal do Espirito Santo, ES, Brasil \\ Silvia Helena Koller \\ Universidade Federal do Rio Grande do Sul, RS, Brasil
}

\begin{abstract}
Resumo
O objetivo deste artigo é caracterizar o convívio de adolescentes em medida socioeducativa de internação com a equipe técnica, a partir da perspectiva dos adolescentes. Foram realizadas entrevistas semiestruturadas com dez adolescentes, entre 16 e 18 anos, internos em uma unidade socioeducativa em Porto Alegre. Um diário de campo também foi preenchido a partir das idas a campo. Os dados foram tratados a partir de uma análise temática e interpretados com base na Teoria Bioecológica do Desenvolvimento Humano. A precariedade da infraestrutura, o número insuficiente de técnicos e a pressão do poder judiciário foram identificados como elementos contextuais que interferiam negativamente sobre os processos proximais entre adolescentes e técnicos. Ainda assim, verificaram-se elementos de reciprocidade e aprendizagem que indicavam o estabelecimento de processos proximais. Investimentos em recursos humanos e materiais e a regulamentação das demandas jurídicas podem favorecer o desenvolvimento de processos proximais entre adolescentes e equipe técnica.
\end{abstract}

Palavras-chaves: Relações interpessoais; Adolescente em conflito com a lei; Medidas socioeducativas; Psicologia do desenvolvimento.

\section{The coexistence of juvenile offenders with the technical team of a treatment facility}

\section{Abstract}

This paper aims to characterize the coexistence of juvenile offenders with the technical team of a treatment facility, from the juvenile offenders' perspective. Semi-structured interviews were conducted with ten juvenile offenders, between 16 and 18 years old, at a treatment facility in Porto Alegre. A field diary was also filled after fieldwork. Data were treated based on thematic analysis and grounded on Bioecological Theory of Human Development. Precariousness of infrastructure, insufficient number of technical team members, and pressure from judiciary were identified as contextual elements that negatively interfered with proximal processes between juvenile offenders and the technical team. Nevertheless, signs of reciprocity and learning were observed, which indicated the establishment of proximal processes. Investments in human and material resources and the regulation of judicial demands may favor the development of proximal processes between juvenile offenders and the technical team.

Keywords: Interpersonal relationship; Juvenile delinquency; Adolescent, institucionalized; Developmental psychology.

\section{La convivencia de adolescentes en medida socioeducativa de internamiento con el equipo técnico}

\section{Resumen}

El objetivo de este artículo es caracterizar la convivencia de adolescentes en medida socioeducativa de internamiento con el equipo técnico, desde la perspectiva de los adolescentes. Se realizó entrevistas semiestructuradas con diez adolescentes, entre 16 y 18 años, internos en una unidad socioeducativa en Porto Alegre. Un diario de campo también se llenó a partir de las asistencias a campo. Los datos fueron tratados a partir de un análisis temático e interpretados con base en la Teoría Bioecológica del Desarrollo Humano. La precariedad de la infraestructura, el número insuficiente de técnicos y la presión del poder judicial fueron identificados como elementos contextuales que interferían negativamente sobre los procesos proximales entre adolescentes y técnicos. Sin embargo, se verificaron elementos de reciprocidad y aprendizaje que indicaban el establecimiento de procesos proximales. Inversiones en recursos humanos y materiales y la regulación de las demandas jurídicas pueden favorecer el desarrollo de procesos proximales entre adolescentes y equipo técnico.

Palabras clave: Relaciones interpersonales; Adolescentes en conflicto con la ley; Medidas socioeducativas; Psicología del desarrollo. 


\section{Introdução}

O objetivo do presente artigo é caracterizar o convívio entre adolescentes em medida socioeducativa (MSE) de internação e sua equipe técnica, a partir da perspectiva dos adolescentes. A ênfase sobre aspectos interpessoais relaciona-se com o aporte teórico utilizado, a Teoria Bioecológica do Desenvolvimento Humano (TBDH). De orientação contextualista, a TBDH evidencia o estudo das interrelações cotidianas conforme percebidas pela pessoa em desenvolvimento (Bronfenbrenner \& Morris, 2006). As relações interpessoais tornam-se elementos ontológicos essenciais a partir da cunhagem do conceito processos proximais (PP). Estes podem ser compreendidos como as interações recíprocas e progressivamente mais complexas entre um organismo humano biopsicologicamente ativo, em evolução, e pessoas, objetos e símbolos presentes no ambiente externo imediato (Bronfenbrenner \& Morris, 2006). Estudos que elucidem essas interações cotidianas no âmbito das MSEs podem orientar intervenções mais precisas, otimizando aspectos positivos e apontando elementos disruptivos que possam prejudicar seu andamento.

As MSEs são medidas judiciais direcionadas a adolescentes autores de atos infracionais. Neste trabalho, é investigada a MSE de internação, considerada a mais severa por privar o adolescente de sua liberdade. A execução da MSE é ordenada pelo Sistema Nacional de Atendimento Socioeducativo (SINASE, Brasil, 2006), que prevê a inserção de equipes técnicas multidisciplinares nos programas socioeducativos. Essas inserções são uma forma de assegurar o atendimento individual e grupal aos adolescentes e seus familiares, em uma perspectiva de garantia de direitos. A equipe técnica deve oferecer um trabalho técnico especializado, que se difere das funções desempenhadas pelos agentes socioeducativos. Estes são funcionários que mantém contato cotidiano com os adolescentes, cuidando da segurança ao mesmo tempo em que promovem ações pedagógicas não especializadas. Os funcionários, juntos, devem direcionar ações pedagógicas, incentivando a participação ativa dos adolescentes e dos seus familiares a partir da formação de vínculo e da "educação por exemplo".

Ainda que os atendimentos técnicos devessem funcionar em uma perspectiva de garantia de direitos, a literatura científica revela que a realidade se caracteriza pela precarização do trabalho e pelo desvio de funções. Uma pesquisa conduzida no Espírito Santo (Aragão, Margotto, \& Batista, 2012) descreveu uma série de ações burocráticas desenvolvidas pela equipe técnica - alocação dos adolescentes, censura das cartas de familiares, organização dos materiais autorizados nas visitas familiares. Essas atribuições se distanciavam da proposta pedagógica prevista ao trabalho técnico socioeducativo. Funcionários entrevistados em um estudo realizado no Rio de Janeiro (Oliveira \& Assis, 1999) revelaram que a execução de seu trabalho era prejudicada pelo excesso de funções institucionais, como a redação de relatórios judiciais. A baixa frequência de atendimentos foi também apontada por uma funcionária em um estudo realizado em São Paulo (Lima, 2006). Um trabalho conduzido no Distrito Federal (Souza \& Costa, 2012) revelou que, muito embora a equipe técnica se propusesse a desenvolver um trabalho socioeducativo, a falta de recursos dificultava a condução das atividades.

A atuação da equipe técnica quanto aos relatórios judiciais foi também posta em crítica em algumas pesquisas. A partir da investigação de pareceres psicológicos e planos individuais de atendimento, estudos revelaram relatos descontextualizados, que individualizavam a conduta infracional dos adolescentes (Castro \& Guareschi, 2008; Scisleski, Bruno, Galeano, Santos, \& Silva, 2015) ou culpabilizavam seus familiares (Medeiros \& Paiva, 2015). Esta conduta legitimava um processo de produção da delinquência. Uma pesquisa etnográfica acompanhou um adolescente em São Paulo (Malvasi, 2011) e identificou que as funções avaliativas da equipe técnica geravam, no participante, a sensação de estar sendo vigiado. Com isso, o adolescente reproduzia comportamentos esperados na tentativa de obter o alvará de soltura.

No que se refere ao convívio entre equipe técnica e adolescentes, pesquisas trouxeram resultados que indicaram relações interpessoais ora positivas e ora negativas. A partir de entrevistas com técnicos e agentes socioeducativos, um estudo sediado no Rio de Janeiro (Oliveira \& Assis, 1999) apontou o estabelecimento de relações pouco amistosas entre adolescentes e funcionários. Os funcionários revelaram, contudo, que conquistavam a confiança de alguns adolescentes, tornando-se referências positivas no cumprimento da MSE. Adolescentes entrevistados em um estudo na Paraíba (Estevam, Coutinho, \& Araújo, 2009) consideraram positivas as relações estabelecidas com os funcionários, que os ajudavam na elaboração de seus projetos de vida. Participantes da mesma pesquisa, porém internos em outra unidade, revelaram que o convívio no local era marcado pela intriga, angústia e desconfiança mútua. Outro trabalho também sediado na Paraíba (Coutinho, Estevam, Araújo, \& Araújo, 2011) indicou diferenças na percepção dos adolescentes com 
relação aos técnicos e monitores, sendo os primeiros considerados amigos e os segundos agressivos.

Os trabalhos apresentados não tinham como objetivo central a investigação sobre as relações interpessoais, havendo uma lacuna na literatura no que se refere aos processos decorridos da situação de privação de liberdade (Coscioni, Costa, Rosa, \& Koller, 2017). É preciso desenvolver estudos que elucidem essas relações cotidianas e destaquem elementos que contribuam para o desenvolvimento das práticas socioeducativas. A TBDH, nesse sentido, aparece como aporte teórico congruente com a proposta de estudar esses processos cotidianos.

A TBDH se constrói tendo como base quatro elementos fundamentais: Processo, Pessoa, Contexto e Tempo. O primeiro elemento é central e articulador dos demais. Considerados a força propulsora do desenvolvimento humano, os PP podem agir no sentido de gerar competências, ou de inibir disfunções. Segundo Bronfenbrenner e Morris (2006) o estabelecimento de PP está condicionado à presença simultânea de cinco aspectos: 1) o engajamento da pessoa em atividades; 2) a ocorrência das atividades com frequência regular e ao longo de um período extenso de tempo; 3) a progressividade cada vez mais complexas das atividades; 4) a reciprocidade das relações; e 5) a composição do ambiente físico imediato com objetos e símbolos que estimulem a atenção, exploração, manipulação e imaginação da pessoa. Exemplos de interrelações cotidianas que podem favorecer o estabelecimento de PP no âmbito das MSEs são: o acompanhamento da equipe técnica aos adolescentes e os contatos estabelecidos semanalmente com os familiares.

Três categorias de características da Pessoa são propostas, que aparecerem no modelo ora enquanto resultados e ora enquanto moderadoras dos PP. As características de força podem ser geradoras ou disruptivas, as primeiras entendidas como as que mantêm e sustentam PP (i.e., curiosidade; responsividade à iniciativa de outrem; etc.), enquanto as segundas os impedem ou interrompem (i.e., impulsividade; agressividade; etc.). As características de recurso referem-se a aspectos físicos, cognitivos, emocionais, sociais e materiais da pessoa, que influenciam o engajamento efetivo em PP (i.e., habilidades; conhecimentos; experiências; etc.) ou inibem tal engajamento (i.e., deficiência física; doenças graves ou persistentes; etc.). Por último, as características de demanda dizem respeito àquelas que podem causar no ambiente reações favoráveis, ou não, ao estabelecimento de PP, tais como idade, gênero e cor (Bronfenbrenner \& Morris, 2006). Os PP estabelecidos entre equipe técnica e adolescentes são moderados por características pessoais de ambos: um adolescente pode se sentir mais confortável em falar com homens (demanda) sobre sua sexualidade; o conhecimento em música (recurso) pode auxiliar o técnico no desenvolvimento das atividades; adolescentes mais proativos (força) podem ter maior facilidade para se engajar nas atividades propostas.

Quatro níveis ecológicos são propostos a fim de explicar diferentes dimensões do Contexto. Microssistema define-se como o ambiente físico em que a pessoa se insere e interage face-a-face com outras pessoas. Mesossistema trata-se do sistema de microssistemas interrelacionados em que a pessoa se insere. Exossistema diz respeito aos ambientes em que a pessoa não promove interações face-a-face, mas que a influenciam em suas relações cotidianas, devido à participação da outra pessoa nos ambientes em que ela não participa. Por último, macrossistema referese aos sistemas institucionais de uma cultura, o que engloba aspectos econômicos, sociais, educacionais, legais e políticos (Bronfenbrenner \& Morris, 2006). No âmbito de aplicação da MSE, podem ser considerados microssistemas a unidade socioeducativa, a sala de aula do adolescente e outras instituições frequentadas, de modo que a interrelação desses microssistemas constitui o mesossistema do adolescente. O Juizado da Infância e da Juventude e a residência dos funcionários e de seus familiares são considerados exossitemas, enquanto que a cultura organizacional e regional são exemplos de macrossistemas.

O Tempo é também apresentado a partir de três conceitos que se relacionam. Dada uma interação entre técnico e adolescente, o estabelecimento de PP está condicionado: 1) a como o adolescente se sente no momento imediato (microtempo) - se está feliz, cansado, etc.; 2) à frequência e extensão com que ocorrem as interrelações cotidiadas (mesotempo) ele é um adolescente, membro de um núcleo familiar, recentemente passou a cumprir uma MSE, etc.; e 3 ) aos acontencimentos históricos, globais e regionais (macrotempo) - a discussão em torno dos projetos de redução da inimputabilidade penal, um período político marcado pela contenção de gastos, etc.

A TBDH foi utilizada de maneira indutiva, lançando luz aos resultados, mas também de maneira dedutiva, na construção do intrumento e na formulação dos objetivos. O objetivo geral deste artigo é caracterizar o convívio entre adolescentes em MSE de internação e a equipe técnica, a partir da perspectiva dos adolescentes. Seus objetivos específicos são: 1) identificar elementos presentes nesse convívio que sugiram o estabelecimento de PP; e 2) detectar elementos contextuais que moderem o estabelecimento desses PP. 


\section{Método}

Trata-se de um estudo qualitativo realizado em uma unidade de internação socioeducativa masculina, localizada na região metropolitana do Rio Grande do Sul. O local possui quatro alas e a pesquisa ocorreu com adolescentes de apenas uma delas. À época de realização das entrevistas, residiam na ala mais de 40 adolescentes em um local projetado para receber 18 . Além da superlotação, a estrutura do local era precária, tanto no que se refere à ausência de espaços para realização das atividades, quanto no que diz respeito à insalubridade e falta de higiene. Faziam parte da equipe técnica que atendia aos adolescentes: um advogado, uma educadora física, uma pedagoga e uma psicóloga. Uma assistente social compunha originalmente a equipe, mas pediu exoneração, sem que um substituto ocupasse seu lugar.

Participaram do estudo dez adolescentes, que foram recrutados com o auxílio de um membro da equipe técnica. A opção por recrutar dez partipantes reflete o entendimento de que com este número se atingiria a saturação dos dados (Lal, Suto, \& Ungar, 2012), o que, de fato, foi observado ao final da análise. A seleção dos participantes ocorreu com base nos sequintes critérios de inclusão: 1) idade entre 15 e 20 anos, evitando-se discrepâncias etárias; e 2) tempo de internação superior a seis meses, considerando este um tempo razoável para a vinculação com outras pessoas. Os nomes citados no artigo são fictícios a fim de se preservar a identidade dos participantes.

Os adolescentes tinham entre 16 e 18 anos e eram majoritariamente de cor branca. A predominância de participantes da cor branca reflete a realidade étnica do RS, como encontrado em outras pesquisas (Nardi \& Dell'Aglio, 2014). A maioria dos participantes $(80 \%)$ frequentava o ensino fundamental II (entre 5o e 9o ano), destacando-se apenas dois adolescentes (20\%) que cursavam o 4 o ano do ensino fundamental. A baixa escolaridade entre adolescentes em MSE pode ser encontrada em outras pesquisas com esta população (Nardi \& Dell’Aglio, 2014).

Foram utilizados como instrumentos uma ficha de identificação, um diário de campo e um roteiro de entrevista semiestruturado. Na ficha de identificação, continham dados biossociodemográficos, socioeducativos e familiares. No diário de campo, registravamse as percepções do pesquisador sobre: 1) o espaço físico; 2) a rotina institucional; 3) a recepção dos funcionários e adolescentes ao pesquisador; e 4) aspectos interpessoais observados entre os adolescentes e funcionários. O roteiro de entrevista semiestruturada continha 30 perguntas abertas divididas em três sessões: 1) funções e atendimentos da equipe técnica; 2) relação interpessoal com o(a) técnico(a) apontado(a) pelo adolescente como o(a) que ele lidava melhor; 3) relação interpessoal com o(a) técnico(a) apontado(a) pelo adolescente como o(a) que ele lidava pior. Quando solicitados a refletir sobre a relação com a equipe técnica, informou-se aos adolescentes que eles poderiam incluir relações com técnicos(as) de outras unidades.

A pesquisa seguiu os critérios éticos expressos na Resolução no 466/2012, do Conselho Nacional de Saúde (Brasil, 2012a). Foi inicialmente aprovada por um Comitê de Ética em Pesquisa com Seres Humanos, bem como pelo presidente da Fundação de Atendimento Socioeducativo do Rio Grande do Sul, que assinou um termo de anuência. Seus objetivos, justificativa, procedimentos e critérios éticos foram explanados aos adolescentes, que assinaram um termo de assentimento ou consentimento livre e esclarecido (a depender da idade). O diretor da unidade assinou os termos de consentimento de participantes menores de idade.

Recrutados os participantes, iniciaram-se os procedimentos formais de coleta de dados. As fichas de identificação foram preenchidas com o auxílio da equipe técnica, que tem acesso aos prontuários dos adolescentes. Os adolescentes foram entrevistados individualmente em ambiente cedido pela instituição, em que a privacidade e conforto foram garantidos. Com o consentimento dos adolescentes, as entrevistas tiveram o áudio gravado. As entrevistas foram conduzidas em novembro de 2015 e tiveram duração média de 19 minutos, variando de 11 a 33 minutos. O entrevistador, homem e jovem, não possuía vínculo anterior com os adolescentes e é de formação em psicologia. Ao final das idas à campo, o pesquisador preenchia um diário de campo, registrando suas percepções e sentimentos durante as atividades de coleta.

Em posse dos dados, iniciaram-se os procedimentos de análise dos dados. Inicialmente, caracterizaramse os participantes a partir dos dados nas fichas de identificação. O conteúdo das entrevistas, por sua vez, foi tratado por meio da Análise Temática (Braun \& Clark, 2006) com o auxílio do software Nvivo 10. Após um período de familiarização com o corpus de análise, foram codificados os trechos das entrevistas que caracterizavam o convívio com a equipe técnica, agrupados posteriormente por similaridade semântica. Iniciou-se um processo de proposição de temas e subtemas a partir de critérios êmicos, isto é: baseados na perspectiva dos próprios participantes. As unidades temáticas foram então revisadas até o ponto em que todos os códigos foram inseridos em categorias mutuamente exclusivas. Os registros em diário de campo também sofreram tratamento, sendo codificados 
os trechos que pudessem trazer informações adicionais ao conteúdo colhido nas entrevistas.

Criados os temas e subtemas, buscaram-se meios de verificar a fidedignidade e validade da análise. As unidades temáticas foram explanadas a um juiz, que, capacitado ao uso do NVivo 10 e ao método de análise, refez a análise a partir dos trechos já destacados nas transcrições. As diferenças entre juízes foram tratadas a partir do consenso, tendo-se reescrito as unidades temáticas. Um terceiro juiz, também capacitado, refez a análise, tendo-se calculado um índice de concordância (Coeficiente Kappa) entre 79\% e 91\%, o que indica fidedignidade e validade da análise segundo os parâmetros de Cohen (1960). O conteúdo tratado foi também apresentado aos dois únicos participantes que ainda permaneciam internos no local, que concordaram com os resultados apresentados e acrescentaram informações que foram incorporadas à análise. Ademais, os membros da equipe de pesquisa envolvidos no projeto de pesquisa não possuíam interesses pessoais ou financeiros que pudessem significar conflitos de interesse.

\section{Resultados}

A análise temática resultou na codificação de 464 trechos, que foram inseridos em nove subtemas, que compuseram três temas. O processo de tratamento dos dados ocorreu de modo a se observar a saturação teórica. Isto é, os conteúdos trazidos pelos participantes tenderam a se repetir, sendo organizados por similaridade semântica em unidades temáticas que explicaram os dados. As unidades temáticas foram descritas simplificadamente na Tabela 1 e cada um dos temas, com seus subtemas, foram descritos detalhadamente em subseções separadas.

\section{Atendimentos Técnicos}

Havia a crença, entre os participantes, de que a função da equipe técnica era ajudar os adolescentes durante o cumprimento da MSE. Ao se referirem à equipe técnica de modo geral ou aos técnicos com quem lidavam melhor, os adolescentes demonstraram satisfação pelos atendimentos. Caracterizaram a equipe técnica como profissional e reconheceram benefícios advindos dela: "Ele(a) me ajudava bastante. Todo tempo que eu fiquei aqui, 95 dias, ele(a) me ajudou" (Marcelo, 17 anos). Quando mencionados os técnicos com quem lidavam pior, foram feitas críticas quanto à forma de trabalho, relatada como antiética, nãoprofissional e sem efeito: "Não é uma reclamação minha, é uma reclamação de diversos já, que ele(a) é um (a) péssimo(a) profissional" (Marcelo, 17 anos). Esses técnicos por vezes dificultavam o cumprimento da MSE. Os adolescentes relataram aprendizagem na relação com os técnicos com quem lidam pior.

TABELA 1

Descrição sumarizada dos temas e subtemas

\begin{tabular}{|c|c|}
\hline Temas & Subtemas \\
\hline \multirow{3}{*}{$\begin{array}{l}\text { Atendimento Técnico: Este tema reúne as percepções sobre as funções, } \\
\text { conteúdos e desfechos dos atendimentos técnicos. A forma como esses } \\
\text { atendimentos eram conduzidos moderava diretamente a maneira como } \\
\text { as relações interpessoais entre adolescentes e equipe técnica eram } \\
\text { estabelecidas }\end{array}$} & $\begin{array}{l}\text { Atendimentos Institucionais: Este subtema retrata os atendimentos } \\
\text { técnicos que funcionavam como uma mediação entre os adolescentes e } \\
\text { as instituições socioeducativas e judiciárias }\end{array}$ \\
\hline & $\begin{array}{l}\text { Atendimentos Pragmáticos: Este subtema revela os atendimentos } \\
\text { técnicos que funcionavam como uma mediação com o meio externo à } \\
\text { instituição, bem como organizavam o cotidiano dos adolescentes }\end{array}$ \\
\hline & $\begin{array}{l}\text { Atendimentos Pedagógicos: Este subtema caracteriza os atendimentos } \\
\text { técnicos que se relacionavam diretamente com os propósitos } \\
\text { pedagógicos previstos ao cumprimento de uma MSE }\end{array}$ \\
\hline \multirow{4}{*}{$\begin{array}{l}\text { Características da Relação: Este tema reúne características das } \\
\text { relações interpessoais estabelecidas pelos adolescentes com a } \\
\text { equipe técnica, fornecendo informações sobre o convívio e interação } \\
\text { cotidianos, incluindo durante os atendimentos técnicos realizados }\end{array}$} & $\begin{array}{l}\text { Proximidade: Este subtema reflete sobre o grau de proximidade e } \\
\text { vinculação entre adolescentes e equipe técnica }\end{array}$ \\
\hline & $\begin{array}{l}\text { Comunicação: Este subtema retrata as características da comunicação } \\
\text { entre adolescentes e equipe técnica }\end{array}$ \\
\hline & $\begin{array}{l}\text { Forma de Tratamento: Este subtema caracteriza a maneira como } \\
\text { adolescentes e equipe técnica se tratavam }\end{array}$ \\
\hline & $\begin{array}{l}\text { Sentimentos: Este subtema revela os sentimentos presentes nos } \\
\text { adolescentes e equipe técnica quando estavam juntos }\end{array}$ \\
\hline \multirow[t]{2}{*}{$\begin{array}{l}\text { Tempo: Este tema reúne informações sobre o tempo que os } \\
\text { adolescentes passavam com a equipe técnica }\end{array}$} & $\begin{array}{l}\text { Frequência: Este subtema traz informações sobre a frequência com } \\
\text { que adolescentes e equipe técnica se encontravam }\end{array}$ \\
\hline & $\begin{array}{l}\text { Duração: Este subtema traz informações sobre o tempo de duração } \\
\text { dos atendimentos técnicos realizados }\end{array}$ \\
\hline
\end{tabular}


Esta aprendizagem, contudo, estava associada a experiências negativas, das quais tiveram algum proveito: "Porque se tu depender de muita pessoa, tu acaba se decepcionando, entendeu? Tem que fazer por ti. No caso, eu aprendi a me virar sozinho com ele(a). Ele(a) me ensinou, com choque, que eu tinha que me virar sozinho" (Marcelo, 17 anos).

Um primeiro subtema descreve os Atendimentos Institucionais, a partir dos quais a equipe técnica mediava o tempo de cumprimento da MSE. Estas ações eram desenvolvidas a partir da participação em audiências, redação de relatórios e outros procedimentos jurídicos: "Ele(a) faz um corre pro cara ir embora de uma vez. Faz um relatório do cara ali também, para o cara largar" (Gustavo, 16 anos). Verificam-se também relatos de que a equipe técnica ajudava os adolescentes a não se envolverem em brigas: "A função deles é ajudar nós a melhorar, não ficar se atrapalhando, brigando. Eles chamam, dão uns conselhos pro cara ir embora mais rápido" (Leonardo, 17 anos). Particular diferença foi relatada entre essas ações se executadas pelos técnicos com quem lidavam melhor, ou pior. Os primeiros agiam no sentido de ajudar, enquanto os segundos prolongavam o tempo de permanência na instituição.

Os adolescentes descreveram um conjunto de Atendimentos Pragmáticos, reunidos em um segundo subtema. Relataram recorrer à equipe técnica quando precisavam se articular com outros serviços, tais como cursos e tratamentos psicológicos e em saúde. Somente os técnicos com quem lidavam melhor foram mencionados como efetivos em tais práticas: "Se eu pedir alguma coisa, eles dão um jeito de conseguir, entendeu? Se está ao alcance deles, eles dão um jeito de conseguir" (Marcelo, 17 anos). Revelaram também que se encaminhavam à equipe técnica quando precisavam obter notícias: "Ele(a) explica uns negócio pra minha familia também, pra minha família não ficar preocupada. Daí, assim, a pessoa se sente melhor também, né?" (Augusto, 18 anos). O veículo de informações foi caracterizado pela transmissão de notícias falsas, de mentiras e pela tentativa de enrolar os adolescentes, quando referidos os técnicos com quem lidavam pior. A transmissão de notícias factíveis, marcada pela sinceridade dos emissores, caracterizava a comunicação com os técnicos com quem lidavam melhor. A equipe técnica também mediava o contato entre adolescentes e seus familiares, gerenciando as visitas familiares: "Eles vão ali e já ligam pro familiar pra ver o que tá dando, o que tá acontecendo, porque eles não tão vindo visitar. Aí o cara começa a pegar visita de novo, porque ele(a) ligou ali pro familiar direitinho" (Marcos, 18 anos).
Intitulou-se Atendimentos Pedagógicos um terceiro subtema, que se refere às ações desenvolvidas relacionadas com os objetivos pedagógicos da MSE. Houve menções a intervenções de apoio psicológico, que acalmavam, tranquilizavam, davam apoio e ânimo, colocavam para cima e aliviavam a pressão psicológica: "No caso, quando eu tou mal, eu peço ajuda pra ele(a). E ele(a) fala pra mim 'Fica sereno, que tudo vai dar certo"' (Leandro, 18 anos). As intervenções técnicas levavam os adolescentes também a se sentirem pessoas melhores, a amadurecem e a discernirem entre o certo $e$ o errado: "Tipo, o tempo que eu tou aqui, já amadureci, já evolui bastante, né? Mas ele(a) sempre me ajudou nisso. Ajudou a me formar, a amadurecer mais. Antes eu saía adolescente, agora já saio pra rua como um homem" (André, 18 anos). Habilidades sociais foram adquiridas, aprendendo a respeitar e tratar bem aos outros, a ser mais educado e a compartilhar com os demais suas ideias: "Acho que aprendi a ser educado, né? A falar melhor com as pessoas. Acho que eu aprendi isso com ele(a)" (Paulo, 17 anos).

Os atendimentos permitiram, por vezes, a reelaboração de experiências passadas, bem como a projeções de futuro: "O que ele(a) me explicou bem foi isso. Que eu posso sair sem dever nada para ninguém, trabalhar e continuar minha vida" (Marcelo, 17 anos). Os adolescentes relataram conversar com os técnicos sobre drogas e medicação, havendo menção a intervenções relacionadas ao consumo abusivo de substâncias. Houve menções também a atendimentos nos quais os adolescentes conversavam sobre sua família: "Às vezes ele (a) também fala muitas coisas pra gente relacionar com a família" (André, 18 anos). A equipe técnica, nesse contexto, favorecia um processo de reaproximação com os familiares.

Os Atendimentos Pedagógicos foram menos mencionados nas entrevistas, sobretudo recordados enquanto exemplos de ações proferidas pelos técnicos com quem lidavam melhor. Na entrevista de validação da análise, Victor (18 anos) informou que apenas os técnicos com quem lidava melhor desempenhavam essas funções. Nos atendimentos com os técnicos com quem lidavam pior, era tratado apenas o básico. Marcelo (17 anos) relatou que as funções pedagógicas proferidas pela equipe técnica eram vistas, em geral, comofavores, de modo que os técnicos se vangloriavam quando as realizavam. Acrescentou que, com o passar do tempo, ele aprendeu a jogar com essas pessoas. Discernia os técnicos que trabalhavam com disposição em ajudar daqueles que só enrolavam os adolescentes - com quem conversava apenas o necessário. Segundo o adolescente, esses técnicos o procuravam apenas pontualmente, com a finalidade de conseguir "uma 
assinatura no papel deles pra provar que te atenderam" (Marcelo, 17 anos).

\section{Características da Relação}

Neste tema, reúnem-se os trechos em que os adolescentes caracterizaram as relações interpessoais estabelecidas com os técnicos. Um primeiro subtema associado a este tema refere-se ao grau de Proximidade entre adolescentes e técnicos. Quando se referiam à equipe técnica de modo geral ou aos técnicos com quem lidavam melhor, os adolescentes compreendiam as relações como marcadas pelo afeto e confiança mútua. Havia comparações com as relações estabelecidas com amigos e familiares. Foi mencionado que a equipe técnica trabalhava com empatia e disposição em ajudar; que desejavam o bem dos adolescentes; e que agiam com bom humor e exprimiam emoções durante os atendimentos: "Ontem mesmo ele (a) falou que gosta de mim, gosta da forma que eu ajo, da forma como eu me refiro a ele(a). É uma pessoa que nós se batemo, né? Uma pessoa admira a outra" (André, 18 anos). As relações estabelecidas com os técnicos com quem lidavam pior foram compreendidas como desafetuosas e marcadas pela desconfiança, apatia, falta de intimidade, desinteresse em ajudar e intenção em prejudicar: "Não sei se ele(a) sentia muita coisa, porque ele(a) levava tudo no modo profissional, mas demais, entendeu? No modo profissional, no modo estatística. Ele(a) não partia pro lado humanitário, entendeu? Eu acho que ele(a) não sentia nada" (Marcelo, 17 anos).

As características da Comunicação foram descritas em um segundo subtema. Os diálogos com os técnicos com quem lidavam melhor eram frequentes, sobre grande diversidade de assuntos e ocorriam com fluidez e marcante interação entre as partes: "Quando eu conversava com ele(a), dava pra ver que ele(a) entrava no assunto. Não eram umas perguntas robóticas, assim, tudo com resposta certa" (Marcelo, 17 anos). No que se refere às relações estabelecidas com os técnicos com quem lidavam pior, os adolescentes compreenderam-nas como mediadas por uma má comunicação. Não se sentiam escutados, conversavam pouco e sobre baixa diversidade de assuntos. Os diálogos eram automáticos e pouco fluidos: "Tu conversava com ele (a) e parecia que tava conversando com as paredes" (Marcelo, 17 anos).

Um terceiro subtema referiu-se à Forma de Tratamento entre adolescentes e equipe técnica. Foi recorrente a ideia de reciprocidade do respeito, mesmo referindo-se aos técnicos com quem lidavam pior: " $E u$ trato do mesmo jeito que ele (a) me trata, com respeito" (Leonardo, 17 anos). Foi também relatado um tratamento normal, não havendo aprofundamento das respostas, ainda que incentivados: "Me tratava, assim, normal entendeu? (...) Não me tratava mal, não me xingava, nem nada" (Marcelo, 17 anos). Os técnicos com quem lidavam pior, contudo, foram por vezes descritos como oferecendo um tratamento autoritário. Não levavam em consideração a opinião e as necessidades dos adolescentes: "Ele(a) tinha um modo de pensar bem diferente do meu e, mesmo estando errado(a), ele(a) batia na tecla que o modo de pensar dele (a) era o certo" (Marcelo, 17 anos). As relações de respeito pareciam, entretanto, protocolares, tal como expresso por Marcelo (17 anos) na entrevista de validação da análise: "o respeito impera aqui dentro, mas tem gente que tem respeito e afeto" (Marcelo, 17 ano).

Os Sentimentos expressos nessas relações compuseram o quarto e último subtema associado a este tema. Sentimentos positivos foram descritos - tais como felicidade, serenidade, proteção e leveza - quando se referiam à equipe técnica de modo geral ou aos técnicos com quem lidavam melhor: "Aqui dentro me sinto, bem dizer, protegido, que eu tou do lado dele(a), né, senhor? Sinto protegido quando ele(a) me ajuda" (Leandro, 18 anos). Foram descritos outros sentimentos ao lidar com os técnicos com quem lidavam pior. Os adolescentes negaram sentir raiva, ainda que houvesse razão em senti-la: "Não tenho raiva, não tenho nada... Normal" (Victor, 18 anos). Foram expressos, todavia, sentimentos negativos, tal como se sentir mal, irritado, com raiva, magoado, decepcionado, preocupado, com pena, inseguros e pouco à vontade: "Mas o sentimento que eu sinto é o sentimento de pena dela mesmo, porque é uma pessoa que não acredita em ninguém" (Marcelo, 17 anos).

\section{Tempo}

Um primeiro subtema refere-se à Frequência dos atendimentos. Os adolescentes relataram que os atendimentos ocorriam quando eram solicitados, mas, ainda assim, em baixa frequência. Essa baixa frequência foi associada ao baixo contingente de técnicos, insuficiente para o atendimento de todos os adolescentes: "Quando o cara quer mesmo, eles não chamam. Tipo, demora pra chamar, porque tem muita gente também pra eles atenderem, né?" (Victor, 18 anos). Os adolescentes informaram que a espera pelos atendimentos era demorada, em especial quando referidos os técnicos com quem lidavam pior: "Eu quase nunca tenho atendimento com ele(a) desde que eu vim pra cá. Eu tive uns dois atendimentos com ele (a)" (Alessandro, 16 anos). Os adolescentes alegaram ainda que deixaram, recusaram, evitaram e não participaram dos atendimentos técnicos. Este tipo de situação ocorreu sumariamente quando referidos os técnicos com quem lidavam pior: "Porque eu nem olho muito pra ele(a), né, senhor? Só assino ali, assino em baixo 
e já saio. Eu não quero atendimento" (Leandro, 18 anos). Em menor escala, alguns adolescentes revelaram que os atendimentos ocorriam frequentemente, principalmente ao se referir aos técnicos com quem lidavam melhor: "Ele(a) dava um jeito de atender todos mais seguidamente" (Marcelo, 17 anos).

A Duração dos atendimentos foi expressa em um segundo subtema. Os adolescentes queixaramse de que o tempo dos atendimentos técnicos era insuficiente: "Eles atendem o cara. Dura o quê? Não dura vinte minutos" (Gustavo, 16 anos). Na entrevista de validação da análise, Marcelo (17 anos) chegou a dizer que os atendimentos, por vezes, não duravam três minutos. Havia técnicos, contudo, que se diferenciavam por realizar atendimentos mais longos.

\section{Os Registros em Diário de Campo}

Os registros em diário de campo revelaram que as condições de trabalho da equipe técnica eram precárias, o que interferia diretamente sobre a qualidade dos atendimentos ofertados. Os técnicos revelaram que, embora o salário fosse bom, a infraestrutura do local não permitia a realização de atividades diferenciadas. Não havia, por vezes, nem espaço para a condução dos atendimentos individuais. A sobrecarga de trabalho foi relatada por uma técnica, que informou que teria de restringir seu tempo de trabalho para a produção de relatórios de atendimento. Essas condições acabavam por ocasionar a diminuição do números de atendimentos técnicos semanais. Era recorrente, por exemplo, que os adolescentes aproveitassem o tempo de permanência dos técnicos na ala - quando eles acompanhavam o pesquisador - para lhes cobrar atendimentos. Foram observadas ainda situações em que a equipe técnica se via dividida entre suas funções pedagógicas e a pressão do poder judiciário para a emissão de relatórios. Um trecho do diário de campo merece destaque:

A equipe técnica trocava opiniões a respeito da redação dos relatórios que deveriam ser enviados ao juiz. Preocupavam-se com o que estava sendo escrito sobre os adolescentes. Ofereci aos funcionários algumas referências sobre redação de relatórios psicossociais relacionados a adolescentes em conflito com a lei. Os funcionários se interessaram e informaram que o texto seria útil. Um(a) técnico(a) exclamou: 'Tá escrito aqui que não devemos escrever o relatório para o juiz e, sim, pensando no desenvolvimento do adolescente'. Os funcionários concordaram que aquilo não ocorria na prática, pois muitas das vezes eles sofriam 'pressão para escrever o que o juiz quer ouvir'. (registro em diário de campo, 08/03/2016).

\section{Discussão}

Os adolescentes reconheceram como funções da equipe técnica sumariamente ações de caráter institucional - redação de relatórios e participação em audiências - e de caráter pragmático - articulação com serviços e intermediação com a família. As ações de caráter pedagógico, nesse sentido, foram raras vezes mencionadas. A prevalência de funções de caráter institucional e pragmático foi encontrada em outras pesquisas (Aragão et al., 2012; Lima, 2006; Oliveira \& Assis, 1999), que relacionaram o resultado ao excesso de demandas atribuídas a um corpo técnico de número insuficiente. Isto parece se relacionar com a carência de investimento do Estado em programas de atendimento socioeducativo (Souza \& Costa, 2012), o que leva à precarização do trabalho e da estrutura física do local. Maiores investimentos em recursos humanos e materiais poderiam significar desfechos mais positivos na execução da MSE no País.

O predomínio das funções institucionais está atrelado à pressão do poder judiciário sobre o trabalho técnico socioeducativo. Uma pesquisa que investigou documentos redigidos por psicólogos de equipes técnicas socioeducativas (Scisleski et al., 2015) observou situação semelhante. Ao verificar o conteúdo dos documentos, identificou-se que eles apresentavam recorrentemente a função de assessorar o juiz em sua função judicial. Essa pressão do poder judiciário sobre o trabalho técnico socioeducativo configura-se como uma irregularidade, posto que promove a transposição de demandas jurisdicionais na esfera executiva.

Ainda que as audiências de reavaliação da MSE devam ser instruídas por um relatório da equipe técnica do programa socioeducativo, este documento deve se ater à descrição da evolução do Plano individual de Atendimento (Brasil, 2012b, Art. 42). Não devem, portanto, ocupar a função de pareceres sobre o desfecho futuro da MSE. Esta dupla função - pedagógica e avaliativa - pode influenciar diretamente as relações entre adolescentes e técnicos. Nessa situação, os primeiros podem enfrentar dificuldades em confiar aos segundos ideias que poderiam prejudicar sua avaliação semestral. Deve-se instruir os funcionários dos sistemas socioeducativos e judiciário acerca da função originária deste documento, de modo a retomar à equipe técnica prioritariamente sua função pedagógica.

Estudos em outros países (Ellis \& France, 2012; Maruna, 2011) apontaram que existe uma contradição entre o trabalho técnico voltado para o atendimento pedagógico e o trabalho técnico voltado à avaliação 
comportamental para produção de provas judiciais. Tal contradição gera sentimentos de desconfiança, silenciamento e a sensação de que os internos estão sendo manipulados ou tratados como objeto de intervenção. Esta situação prejudica a possibilidade de abertura e confiança mútua necessárias para um trabalho efetivo de atenção a necessidades pedagógicas. A percepção de uma contradição entre estas duas funções pode explicar a baixa ênfase atribuída ao atendimento pedagógico como função da equipe técnica.

Os dados sugerem, portanto, que aspectos contextuais de diferentes níveis ecológicos influenciam o estabelecimento de PP entre adolescentes e técnicos. Aspectos microssistêmicos foram observados, relacionados à precariedade da infraestrutura física da unidade. Isto prejudicava a qualidade e a frequência dos atendimentos. A baixa frequência de contato e a duração insuficiente dos atendimentos esteve mais relacionada à figura dos técnicos com quem lidavam pior. Isto corrobora a compreensão de que o contato infrequente está relacionado à dificuldade de estabelecimento de PP. Um ambiente que não favorece a estimulação da atenção, exploração, manipulação e imaginação da pessoa em desenvolvimento pode também prejudicar o estabelecimento de PP. Tal situação encontra-se em desacordo com o SINASE (Brasil, 2006), que delimita como princípio socioeducativo a incolumidade, integridade física e segurança.

Aspectos exossistêmicos também se relacionaram a dificuldades de estabelecimento de $\mathrm{PP}$ - seja referente aos órgãos administrativos que financiam os órgãos de atendimento, seja concernente aos órgãos judiciais que influenciam o trabalho da equipe técnica. A falta de investimento financeiro prejudica a infraestrutura do local e promove a defasagem do número de técnicos. A pressão do judiciário pode agir no sentido de direcionar os atendimentos técnicos e as expectativas dos adolescentes com relação a eles. Ao invés de esperar da equipe técnica atendimentos que promovessem seu desenvolvimento a partir de uma perspectiva pedagógica, os adolescentes esperavam que a equipe promovesse a antecipação do fim da MSE. O não cumprimento de tal função apareceu frequentemente como justificativa para caracterizar os técnicos com quem lidavam pior.

A cultura organizacional apareceu como elemento macrossistêmico que moderava o estabelecimento de PP com a equipe técnica. Recorrentemente foi aderida aos técnicos a função de adequar os adolescentes à cultura organizacional, intervindo de modo a os auxiliar a não se envolver em conflitos. Estas intervenções foram frequentemente associadas à antecipação do fim da MSE, de modo que sobretudo aspectos extrínsecos pareciam motivar os adolescentes no controle de sua agressividade. A qualificação das relações como marcadas pelo respeito e bom tratamento, inclusive aquelas estabelecidas com os técnicos com quem lidavam pior, corrobora essa afirmação. Isto porque comportamentos agressivos poderiam significar uma má avaliação com consequente pedido de manutenção da MSE.

A ênfase sobre funções pragmáticas e institucionais parece se relacionar também a uma crença, difundida entre os adolescentes, de que a equipe técnica não é responsável por promover mudanças em suas trajetórias de vida. Estas seriam responsabilidades atribuídas aos próprios adolescentes. Esta crença foi observada em entrevistas com adolescentes em MSE no interior do RS (Muller, Barboza, Oliveira, Santos, \& Paludo, 2009). Os participantes perceberam a desvinculação infracional como um processo que ocorre a partir de atributos e motivações pessoais dos adolescentes, e não do efeito da MSE. Essa crença desfavorece, assim, a recriprocidade necessária para o estabelecimento de PP.

As ações de caráter pedagógico estavam relacionadas aos técnicos com quem lidavam melhor. Ademais, não eram reconhecidas como funções técnicas, mas como uma espécie de favor prestado. A proximidade com os técnicos com quem informavam melhor relacionamento, está associada com o entendimento de que PP são mais efetivos quando estabelecidos entre pessoas com quem se mantém um apego forte (Bronfenbrenner \& Morris, 2006). Ademais, características pessoais de força dos técnicos com quem lidavam melhor, foram destacadas como geradoras de PP - tais como empatia, comunicação assertiva, bom humor e disposição em ajudar.

Ainda que verificada uma avaliação frequentemente positiva ao convívio estabelecido com a equipe técnica, não se pode afirmar que houve o estabelecimento de PP. Isto porque o instrumento da pesquisa não se ateve aos processos estabelecidos entre adolescentes e técnicos, mas às percepções dos primeiros sobre o convívio com os segundos. Todavia, alguns elementos referentes ao convívio com os técnicos com quem lidavam melhor trazem indícios de que PP ocorriam entre eles. Além dos elementos já descritos de reciprocidade, houve relatos de aprendizagem decorrentes dos atendimentos realizados. O instrumento não previu, entretanto, questões que investigassem as atividades desenvolvidas nos atendimentos. Uma análise pormenorizada dessas atividade poderia investigar o engajamento dos adolescentes, bem como uma possível complexidade progressiva em seu transcurso. 


\section{Considerações finais}

O presente estudo caracterizou o convívio entre adolescentes em MSE de internação e a equipe técnica, a partir da perspectiva dos adolescentes. Esse processo de caracterização deu-se a partir da proposta de um estudo qualitativo, de perspectiva êmica, o que permitiu o acesso a informações inovadoras na literatura científica brasileira. Essas informações podem ser utilizadas como forma de aprimorar o atendimento socioeducativo, principalmente ao se levar em consideração que o SINASE (Brasil, 2006) assume os adolescentes como participantes ativos em seu processo socioeducativo. Pesquisas que explorem a percepção da equipe técnica poderiam lançar luz ao fenômeno de maneira bidirecional.

Os resultados sugeriram que o convívio com a equipe técnica foi influenciado por aspectos contextuais de diferentes níveis ecológicos, que moderavam o estabelecimento de PP. Nesse sentido, observou-se que a precariedade da infraestrutura e o número insuficiente de técnicos estavam fortemente atrelados à falta de investimento dos órgãos administrativos. Esta situação vinculava-se à baixa frequência dos atendimentos e a um ambiente físico pouco propício ao engajamento em atividades. Elementos da cultura organizacional e a pressão do poder judiciário, por sua vez, pareceram associados ao entendimento de que a equipe técnica tinha por função, sobretudo, ações de caráter institucional e pragmático. Ações com finalidade pedagógicas eram concebidas como favores prestados por técnicos mais próximos.

Devido a limitações do instrumento da pesquisa, não foi possível afirmar se houve, ou não, o estabelecimento de PP entre adolescentes e equipe técnica. Careceram informações sobre os processos decorrentes dessas relações cotidiadas, observando: 1) o engajamento dos adolescentes nas atividades desenvolvidas com os técnicos; e 2) uma possível complexidade progressiva no transcorrer desses atendimentos. Ainda assim, foi possível verificar indícios de reciprocidade e aprendizagem a partir da relação com os técnicos com quem os adolescentes lidavam melhor. Esses são possíveis indicadores de estabelecimento de PP, propulsores de autoestima e de relações interpessoais positivas com os familiares. Novos instrumentos, de perspectiva qualitativa e quantitativa podem ser pensados a fim de acessar o estabelecimento de PP durante o cumprimento da MSE.

\footnotetext{
Referências

Aragão, E. M. A., Margotto, L. R., \& Batista, R. (2012). Uma cidade-internação e suas multipli(cidades): Encontros com adolescentes em cumprimento de medida socioeducativa. EPOS, 3(2), 1-21.

Brasil. Ministério da Saúde. Conselho Nacional de Saúde. (2012a). Resolução nº 466, de 12 de Dezembro de 2012. Brasília, DF: Diário Oficinal da União.

Brasil. Presidência da República. Secretaria Especial dos Direitos Humanos. Conselho Nacional dos Direitos das Crianças e dos Adolescentes. (2006). Sistema Nacional de Atendimento Socioeducativo. Brasília, DF: Autor.

Brasil. Presidência da República. Casa Civil. Subchefia para Assuntos Jurídicos. (2012b). Lei federal n. 12.594, de 18 de janeiro de 2012. Institui o Sistema Nacional de Atendimento Socioeducativo. Brasília, DF: Diário Oficinal da União. Braun, V. \& Clarke, V. (2006). Using thematic analysis in psychology. Qualitative Research in Psychology, 3, 77-101. http://dx.doi.org/10.1191/1478088706qp063oa

Bronfenbrenner, U. \& Morris, P. A. (2006). The bioecological model of human development. In W. Damon (Series Org.) \& R. M. Lerner (Vol. Org.). Handbook of child psychology: Theoretical models of human development (pp. 793-828). New York: John Wiley \& Sons.

Castro, A. L. S. \& Guareschi, P. (2008). Da privação da dignidade social à privação da liberdade individual. Psicologia \& Sociedade, 20(2), 200-207. http://dx.doi.org/10.1590/S010271822008000200007

Cohen, J. (1960). A coefficient of agreement for nominal scales. Educational and Psychological Measurement, 20(1), 37-46. https://doi.org/10.1177/001316446002000104

Coscioni, V., Costa, L. L. A., Rosa, E. M., \& Koller, S. H. (2017). O cumprimento da medida socioeducativa de internação no Brasil: Uma revisão sistemática da literatura. Psico, 48(3), 231-242. http://dx.doi.org/10.15448/19808623.2017.3.24920

Coutinho, M. D. P. L., Estevam, I. D., de Araújo, L. F., \& Araújo, L. S. (2011). Prática de privação de liberdade em adolescentes: Um enfoque psicossociológico. Psicologia em Estudo, 16(1), 101-109. http://dx.doi.org/10.1590/S1413 73722011000100012

Ellis, K. \& France, A. (2012). Being judged, being assessed: Young people's perspective of assessment in youth justice and education. Children \& Society, 26, 112-123. https://doi.org/10.1111/j.1099-0860.2010.00328.x
} 
Estevam, I. D., Coutinho, M. D. P. L., \& Araújo, L. F. (2009). Os desafios da prática socioeducativa de privação de liberdade em adolescentes em conflito com a lei: Ressocialização ou exclusão social? Psico, 40(1), 64-72.

Lal, S., Suto, M., \& Ungar, M. (2012). Examining the potential of combining the methods of grounded theory and narrative inquiry: A comparative analysis. The Qualitative Report, 17(21), 1.

Lima, R. D. C. P. (2006). Mudança das práticas socioeducativas na FEBEM-SP: As representações sociais de funcionários. Psicologia \& Sociedade, 18(1), 56-62. http://dx.doi.org/10.1590/S0102-71822006000100008

Malvasi, P. A. (2011). Entre a frieza, o cálculo e a "vida loka": Violência e sofrimento no trajeto de um adolescente em cumprimento de medida socioeducativa. Saúde \& Sociedade, 20(1), 156-170. http://dx.doi.org/10.1590/S010412902011000100018

Maruna, S. (2011). Why do they hate us? Making peace between psychology and prisoners: Making peace between prisoners and psychology. International Journal of Offender Therapy and Comparative Criminology, 55(5), 671-675. https://doi.org/10.1177/0306624X11414401

Medeiros, F. C. \& de Paiva, I. L. (2015). A convivência familiar no processo socioeducativo de adolescentes em privação de liberdade. Estudos e Pesquisas em Psicologia, 15(2),568-586. http://dx.doi.org/10.12957/epp.2015.17659

Muller, F., Barboza, P. D. S., Oliveira, C. C. D., Santos, R. R. G. D., \& Paludo, S. D. S. (2009). Perspectivas de adolescentes em conflito com a lei sobre o delito, a medida de internação e as expectativas futuras. Revista Brasileira Adolescência e Conflitualidade, 1(1), 70-87.

Nardi, F. L. \& Dell'Aglio, D. D. (2014). Trajetória de adolescentes em conflito com a lei após cumprimento de medida socioeducativa em meio fechado. Psico, 45(4), 541-550. https://doi.org/10.15448/1980-8623.2014.4.12978

Oliveira, M. B. \& Assis, S. G. (1999). Os adolescentes infratores do Rio de Janeiro e as instituições que os "ressocializam" - A perpetuação do descaso. Cadernos de Saúde Pública, 15(4), 831-844. http://dx.doi.org/10.1590/S0102311X1999000400017

Scisleski, A. C. C., Bruno, B. S., Galeano, G. B., Santos, S. N. D., \& Silva, J. L. C. D. (2015). Medida socioeducativa de internação: Estratégia punitiva ou protetiva? Psicologia \& Sociedade, 27(3), 505-515. http://dx.doi.org/10.1590/1807$03102015 v 27 n 3 p 505$

Souza, L. A. \& Costa, L. F. (2012). Aspectos institucionais na execução da medida socioeducativa de internação. Revista Psicologia Política, 12(24), 231-245.

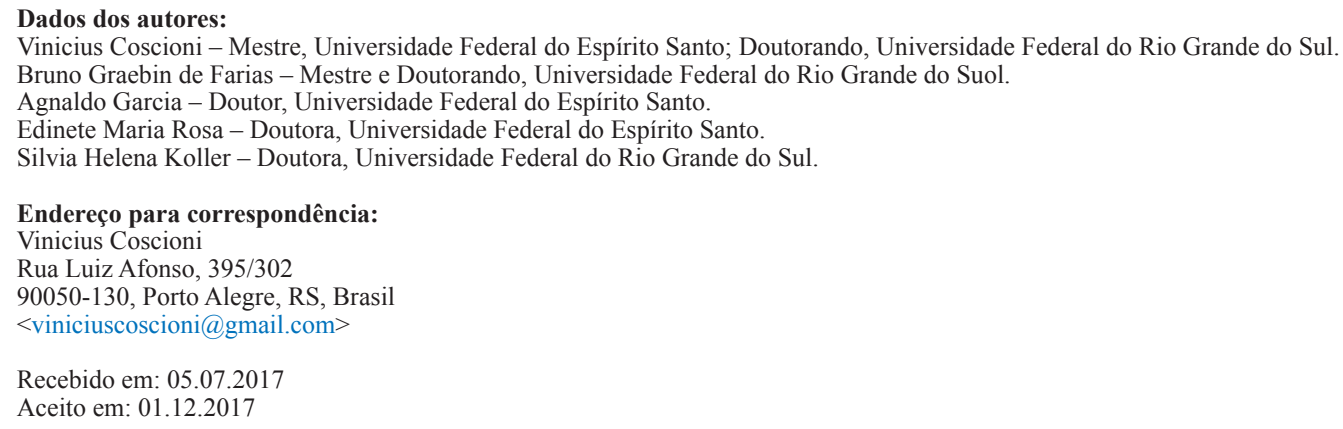

